\title{
Recovery of water and contaminants from cooling tower plume
}

\author{
Francesca Macedonio ${ }^{1,2^{\dagger}}$, Mirko Frappa ${ }^{1}$, Adele Brunetti ${ }^{1}$, Giuseppe Barbieri ${ }^{1}$, Enrico Drioli ${ }^{1,2}$ \\ ${ }^{1}$ National Research Council - Institute on Membrane Technology (ITM-CNR), The University of Calabria, cubo 17C, Rende (CS), 87036, Italy \\ ${ }^{2}$ Department of Environmental and Chemical Engineering, University of Calabria, Rende (CS), 87036, Italy
}

\begin{abstract}
Membrane assisted condenser is an innovative membrane operation that exploits the hydrophobic nature of microporous membranes to promote water vapor condensation and recovery. It can be used for water and chemicals recovery from waste gaseous streams. In this work, the testing of membrane condenser for water and ammonia recovery from synthetic streams (i.e., a saturated air stream with ammonia) simulating the plume of cooling tower is illustrated. The modeling of the process was carried out for predicting the membrane-based process performance and for identifying the minimum operating conditions for effectively recovering liquid water. The experimental data were compared with the results achieved through the simulations showing good agreement and confirming the validity of the model. It was found that the recovery of water can be increased growing the temperature difference between the plume and the membrane module (DT), the relative humidity of the plume $\left(\mathrm{RH}^{\text {plume }}\right)$ and the feed flow rate on membrane area ratio. Moreover, the concentration of $\mathrm{NH}_{3}$ in the recovered liquid water increased with the growing DT, at increasing $\mathrm{NH}_{3}$ concentration in the fed gaseous stream and at growing relative humidity of the feed.
\end{abstract}

Keywords: Membrane condenser, Plume of cooling tower, Water recovery

\section{Introduction}

International awareness has been increasing in recent years, in particular for what concerns the importance of minimizing the scarcity of potable water and the impact of air, water, and solid waste pollutants. One area that has received a considerable amount of attention is the problem of industrial wastewater treatment $[1,2]$. In industrial processes, the recycling and reusing of process streams and, in particular, of water, is necessary for minimizing fresh water requirements. For example, in power plants the two main sources of emissions are from the stack and the cooling towers. Streams emitting from a stack become saturated in the desulfurization step, and the streams from cooling towers are typically river or seawater evaporated to cool the steam cycle stream. If the evaporated water can be effectively recovered, it can represent a real new source of high quality water, to be utilized both at industrial (as make-up water) and at human level (as drinkable water). The main traditional technologies for the capture of evaporated water by gaseous streams are: heat exchangers, absorption, adsorption, and membranes. Implementation of heat exchangers to condense out the water vapor is an obvious option that has been considered for a long time [3, 4]. An example can be found in the project "Recovery of water from boiler flue gas" funded by the U.S. Department of Energy, under Award No. DE-FC2606NT42727 [5, 6]. The condensing heat exchanger apparatus, developed and tested, consisted of a long rectangular duct containing water-cooled heat exchangers arranged in series. Hot flue gas entered the apparatus from the back end of the boiler and was cooled as it passed through the heat exchangers. Condensation in flue gas is a complicated phenomenon since heat and mass transfer of water vapor and various acid vapors simultaneously occur in the presence of noncondensable gases. As a consequence, the condensed water is relatively dirty and corrosive. Therefore, the recovered water is typically of low quality that requires further treatment, and the infrastructure is inherently prone to corrosion over time, appending additional maintenance cost.

Another technique available to remove water vapor from gas streams is using a desiccant drying system [7, 8]. Siemens Power Generation, Inc. and the Energy \& Environmental Research Center, at the University of North Dakota, performed a U.S. Department of Energy supported pilot-scale program that checked the technical viability of a liquid desiccant-based dehumidification technology to efficiently extract water from the power plant flue gas [9]. In
This is an Open Access article distributed under the terms of the Creative Commons Attribution Non-Commercial License (http://creativecommons.org/licenses/by-nc/3.0/) which permits unrestricted non-commercial use, distribution, and reproduction in any medium, provided the original work is properly cited.

Copyright (C) 2020 Korean Society of Environmental Engineers
Received May 29, 2018 Accepted March 13, 2019

${ }^{\dagger}$ Corresponding author

Email: f.macedonio@itm.cnr.it; macedonio@unical.it

Tel: +39-984-492012 Fax: +39-984-402103

ORCID: 0000-0002-8243-3963 
particular, Copen et al. [10] designed a pilot scale Water Extraction from Turbine Exhaust system to recover water vapor, and declare that the system can remove $23-63 \%$ water vapor from flue gas by volume. However, a desiccant system has as disadvantages the regeneration of the desiccant and the low quality of the produced water.

Membrane technology has been researched as a promising option to recover evaporated water. Many works exist that employ dense membranes that selectively permeate water vapor over other gases with excellent selectivity and permeability, reaching above $10^{7}$ $\left(\mathrm{H}_{2} \mathrm{O} / \mathrm{N}_{2}\right)$ and $10^{5}$ barrer $[11,12]$. However, the evaporated water through the cooling tower and stack leaves at near atmospheric pressure, requiring additional compression or vacuum to apply the necessary driving force for separation. Hence, current vapor separation membranes are completely limited by pressure ratio [13] and mass transfer resistance [11].

Supported liquid membranes (thus combining advantages of absorbent and membranes) [14] were also employed but the work is largely in the research stage without accurate economic analysis.

A hydrophilic porous membrane device was developed in one of the projects supported by U.S. Department of Energy's (DOE) National Energy Technology Laboratory. The developed nanoporous ceramic membrane device (called Transport Membrane Condenser (TMC) [15-18]) condenses water and recovers heat from flue gas. Water vapor contained in the flue gas condenses inside the membrane nanopores and passes through by direct contact with low temperature water from the permeate side. In this way, the transported water is recovered along with virtually its whole latent heat. Non-condensable gases such as $\mathrm{CO}_{2}, \mathrm{O}_{2}, \mathrm{NO}_{\mathrm{x}}$, and $\mathrm{SO}_{2}$ are supposed to be inhibited from passing through the membrane by the condensed water clogging the tube membrane pores. The recovered water is of high quality and mineral free and therefore can be used directly as boiler makeup water, as well as for other processes.

Not only tubes of alumina coated with a final coating of Zirconium dioxide but also other membrane materials (such as polyethersulphone, mixed cellulose ester (e.g., cellulose triacetate) and polyvinylchloride) were used in hydrophilic membrane-based dehumidifiers [19]. The advantage in the use of these materials for separating water vapor from the vapor/gas mixture is their strong affinity to the water molecules. More recent works by Zhao et al. [20, 21], Chen et al. [22, 23] and Kim et al. [24] further investigated the efficacy of TMC configurations. In particular, Kim et al. [24] found that TMC is completely limited by the rate of condensation, and proper membranes and an effective module design must be developed for enhancing the vapor pressure gradient.

Another technology currently investigated for water recovery from waste gaseous stream is membrane-assisted condenser (MC). The latter belongs to the class of membrane contactors where microporous hydrophobic membranes are used not as selective barriers but for promoting water vapor condensation and recovery from humidified gaseous streams (e.g., flue gas, plume, etc.). Its working principle was recently introduced by Drioli and co-workers [25-29] (Fig. S1). In details, membrane condenser feed is a gaseous stream, at a certain temperature and, in most of the cases, water saturated. It is fed to the membrane condenser module whose temperature is equal or lower than the one of the feed. In doing this, water droplets already present in the feed together with the amount that condenses onto the membrane surface (and in the membrane module) are blocked by the hydrophobic nature of the membrane. Therefore, the liquid water is recovered at the retentate side, whereas the other gases at the permeate side of the membrane unit. The hydrophobic nature of the membranes not only avoids water droplets dragging, but promotes vapour condensation exploiting the principle of dropwise condensation where, when condensation takes place on a surface that is not wet by the condensate, water beads up into droplets and rolls off the surface. Water vapor preferentially condenses on solid surfaces rather than directly from the vapor because of the reduced activation energy of heterogeneous nucleation in comparison to homogeneous nucleation [30,31]. While the excess energy of a surface controls the heterogeneous nucleation process, it also determines the wetting behavior of the condensate, which has a significant impact on the overall performance. However, the effect of surface-structure geometry on condensation behavior remains under debate. What it is sure is that the use of hydrophobic surfaces improves heterogeneous condensation and recently, the use of hydrophobic surfaces structured at capillary length scales was proposed to enhance heterogeneous condensation [30, 32, 33].

Moreover, in a membrane condenser unit, the modulation of contact time between saturated stream and membrane, as well as the control of temperature and/or pressure difference between membrane sides, allow controlling the fraction of components present in the feed gaseous stream that will be retained in the condensed water. Membrane condenser technology was initially developed in the FP7 CAPWA project (Capture of evaporated water with novel membranes) [34], and it is now further studied and scaled up in the framework of the EU Horizon 2020 project MATChING (Materials \& Technologies for Performance Improvement of Cooling Systems performance in Power Plants) [35]. In both projects, membrane condenser was and is utilized for the recovery of evaporated water from humidified waste gaseous streams. In particular, membrane condenser was used in CAPWA for water recovery from flue gas (i.e., a waste gaseous stream at high temperature containing $\mathrm{SO}_{\mathrm{x}}, \mathrm{NO}_{\mathrm{x}}$ and particles) whereas, currently, in MATChING project it is developed for water recovery from plume of cooling tower (i.e., the stream of saturated exhaust air leaving the cooling tower). Plume temperature is relatively low with respect to that of flue gas. Moreover, the drift of fine droplets emitted from the cooling towers can contain salts (in particular when seawater is utilized as make-up water), biocides and algaecides. These are dosed to the circulating cooling water to prevent growths of micro-organisms such as bacteria, fungi and algae that could interfere with the continuous flow of the water and reduce the heat transfer efficiency of the cooling tower. A normal industrial practice is to use two biocides, such as oxidizing and non-oxidizing types to complement each other's strengths and weaknesses, and to ensure a broader spectrum of attack. Another very important reason for using biocides in cooling towers is to prevent the growth of Legionella. Various studies have shown that from 40 to $60 \%$ of cooling towers tested contained Legionella [36]. Biocidal substances and products used as anti-fouling agents 
are, for example chlorine (used as a short-life biocide in industrial water treatment) and certain types of quaternary ammonium compounds (added to industrial water systems to act as an algicide, protecting the water from infestation and growth of algae). The emission of these compounds in the atmosphere significantly affects the air quality in the areas near the plant; therefore, membrane condenser can be considered as an efficient pre-treatment unit able to both separate water vapour contained in waste gaseous streams, also retaining some of the most effective contaminants that, when discharged in the atmosphere, affect air quality.

In this manuscript, we analyzed, both theoretically and experimentally, the use of membrane condenser for the recovery of water vapor from the plume of a cooling tower. A membrane condenser prototype with $0.0258 \mathrm{~m}^{2}$ of active membrane area was used for the treatment of a gaseous stream simulating the plume (that is, for the reasons listed above, a water saturated air stream containing ammonia). The results of the experiments were utilized for the validation of the simulation study of the process. The latter allows predicting the membrane-based process performance in a wide range of operating conditions and identifying the minimum operating conditions for effectively recovering liquid water.

\section{Materials and Methods}

\subsection{Membrane Condenser Prototype}

Fig. 1 shows the scheme of the membrane condenser prototype built up for performing the measurements.

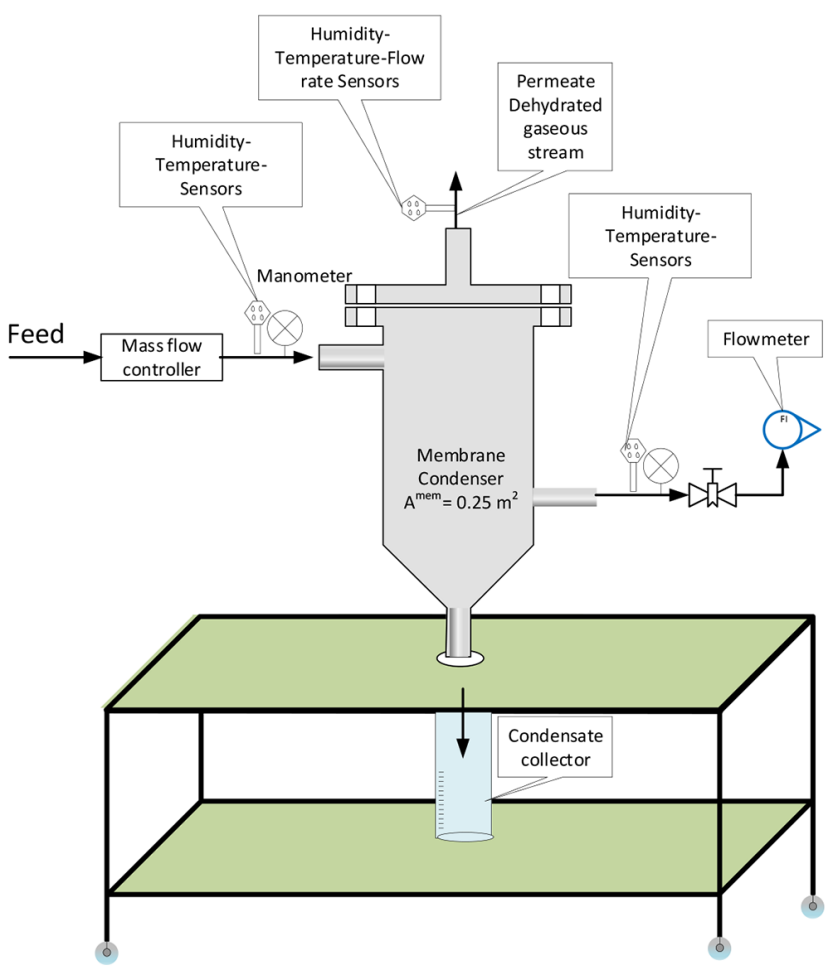

Fig. 1. Scheme of the MC prototype.
The membrane module made in stainless steel with four inlet/outlet lines, is placed in a chamber set at a temperature equal or lower than the one of the gaseous stream for maintaining the required temperature difference between the feed (i.e., the plume) and the membrane module. Nineteen microporous hydrophobic polypropylene commercial membranes are assembled in the module by only one fixed end for an active membrane area of about $258 \mathrm{~cm}^{2}$. According to manufacturer's data (Membrana), each membrane used (3M ${ }^{\mathrm{TM}}$ Capillary Membrane MF-PP Series, Type S6/2) has inner diameter equal to $1.8 \mathrm{~mm}$, wall thickness of 450 micron and nominal pore size of 0.20 micron. The humidified gaseous stream, consisting of saturated or super saturated air with ammonia, is fed to the upper part of the module by a mass flow controller; the membrane allows the liquid water to be retained in the retentate side and collected at the bottom of the module, opportunely designed with a conic shape to avoid stagnant zones, whereas the dehydrated stream is recovered in the permeate side. In dependence on the operating conditions used during the experiments, the permeate stream could contain a certain level of relative humidity, lower than the feed one, and a part of the gaseous stream fed to the module could not pass through the membrane remaining in the retentate side. Indeed, for all the streams, relative humidity and temperature sensors are placed at the inlet and at the outlet of the permeate and retentate streams. A back-pressure controller is placed on the retentate side and the pressure is measured by means of a manometer. All the lines connecting the module with the rest of the instrumentation placed out of thermostatic chamber are thermally insulated in order to avoid any undesired condensation.

The composition of the recovered liquid water is analysed by an ionic chromatography Thermo Scientific Dionex Integrion System.

Table S1 summarizes the operating conditions used in the experiments.

The experimental results are reported in terms of water recovery, defined as the mass of liquid water retained in the retentate side with respect to the total water contained as vapor in the gaseous feed stream (Eq. (1)):

$$
\begin{aligned}
& \text { Water recovery }= \\
& \quad \frac{\text { Liquid water retained in the retentate side }}{\text { Total water contained in the feed stream }} \times 100, \%
\end{aligned}
$$

\subsection{Membrane Condenser Simulations}

Modeling and simulations of membrane condensers were carried out to explore the effect of some process parameters (such as temperatures of plume and module, temperature difference (T) between plume and module, feed flow rate $(\mathrm{Q})$ on membrane area (A) ratio $(\mathrm{Q} / \mathrm{A})$ on membrane condenser performance, and considering a wider range of operating conditions with respect to that used for experiments. For set cases, they were also compared with the experimental results. Detailed relations and models for transport phenomena through the membrane condenser are outside the scope of this work and details can be found in cited literature $[25,27]$. The results of the simulation give indications on the amount of recovered liquid water, on its composition and on the 


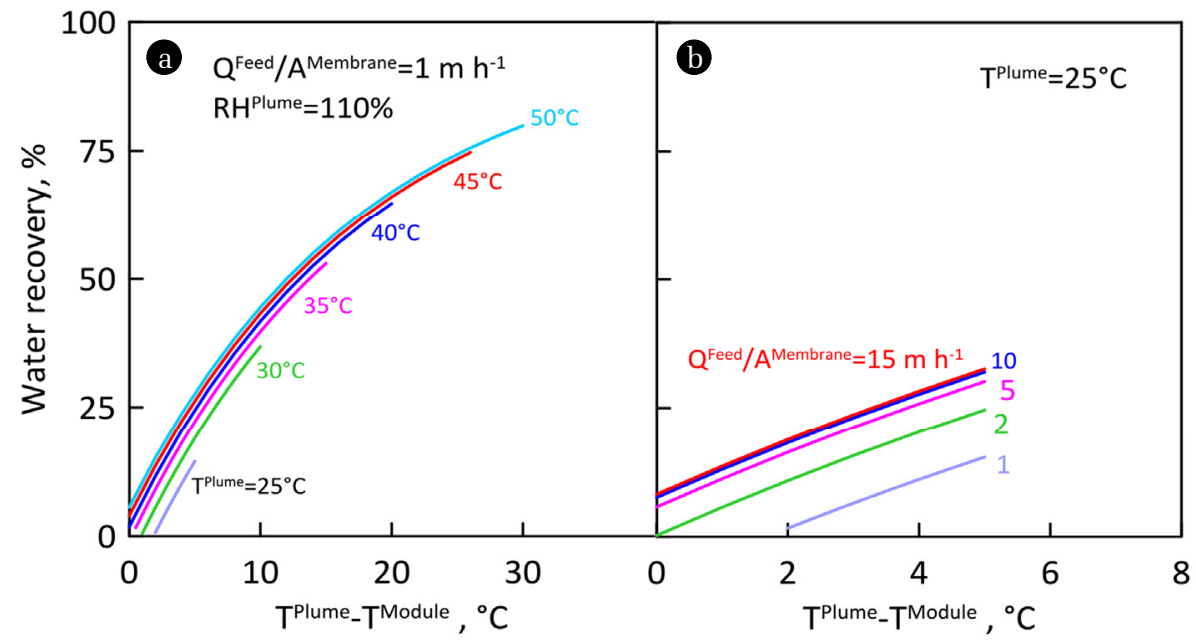

Fig. 2. Water recovery as a function of temperature difference between the plume and the membrane module. Relative humidity of the plume $\left(R H^{\text {Plume }}\right)=110 \% . A=0.026 \mathrm{~m}^{2}$. (a) Water recover at different values of $T^{\text {Plume }}$ and $Q^{\text {Feed }} / \mathrm{A}^{\text {Membrane }}=1$. (b) Water recovery at different values of $\mathrm{Q}^{\text {Feed }} / \mathrm{A}^{\text {Membrane }}$ and $\mathrm{T}^{\text {Plume }}=25^{\circ} \mathrm{C}$.

energy consumption of the process.

Fig. 2(a) shows the effect of cooling on the amount of recovered water. It can be observed that lower temperatures of the feed gaseous stream require larger $\mathrm{T}$ (temperature difference between the feed and the gas before entering the membrane module) for achieving a positive amount of recovered water.

The recovery of water can be improved acting on the ratio Q/A, as it can be seen in Fig. 2(b) showing the amount of water that can be recovered from a plume at $25^{\circ} \mathrm{C}$ when $\mathrm{Q} / \mathrm{A}$ ranges from 1 to $15 \mathrm{~m} \mathrm{~h}^{-1}$.

Simulations indicate that for obtaining positive amount of recovered water, either a $\mathrm{Q} / \mathrm{A}$ ratio $\geq 2 \mathrm{~m} / \mathrm{h}$ or $\mathrm{T} \geq 2{ }^{\circ} \mathrm{C}$ (if $\mathrm{Q} / \mathrm{A}=1$ $\mathrm{m} / \mathrm{h}$ ) are necessary when $\mathrm{T}_{\text {plume }}=25^{\circ} \mathrm{C}$. Less stringent conditions are instead required at $\mathrm{T}_{\text {plume }}$ equal to $30^{\circ} \mathrm{C}$ where a $\mathrm{Q} / \mathrm{A}$ ratio $\geq 2$ or $\mathrm{T} \geq 1$ (if $\mathrm{Q} / \mathrm{A}=1 \mathrm{~m} / \mathrm{h}$ ) have to be utilized.

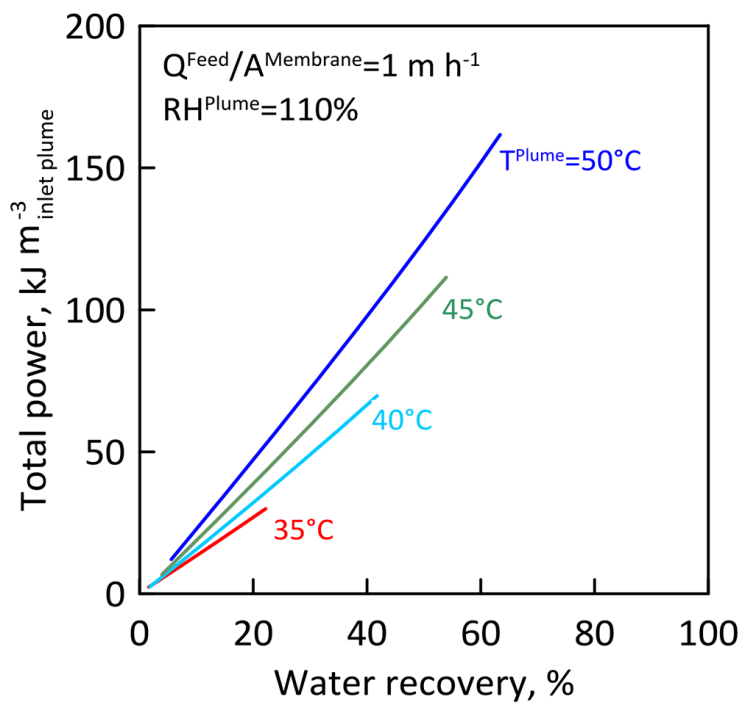

Fig. 3. Power needed to drive the process as a function of water recovery.
For what concenrs the energy consumption of the membrane condenser, Fig. 3 shows the condenser heat duty at different temperature $\left(\mathrm{T}_{\text {plume }}\right)$ of a supersatured $(\mathrm{RH}=110 \%)$ plume. It can be seen that the power needed for achieving the same percentage of recovered water increases with initial feed temperature, although the temperature reduction required for obtaining the desired percentage of water recovery decreases with $\mathrm{T}_{\text {plume }}$ (Fig. 2(a)). This is due to the fact that, at increasing temperature and constant $\mathrm{RH}$, the amount of water vapor in the gaseous mixture is higher. Therefore, for achieving the same percentage of water recovery, a higher volume of water has to be condensed requiring a higher heat duty.

\section{Experimental Measurements}

As reported in Table S1, experimental measurements were carried out at various temperature of the fed gaseous stream (i.e., temperature of the plume), $\mathrm{RH}$ of the feed, at various temperature difference DT between the plume and the module, at two different $\mathrm{Q} / \mathrm{A}$ values, and at various $\mathrm{NH}_{3}$ concentration in the feed.

Fig. 4 shows the recovered water at around $25^{\circ} \mathrm{C}$ for $\mathrm{T}$ ranging from 5 to $12^{\circ} \mathrm{C}$. It can be seen that the amount of recovered water increases at growing $\mathrm{T}$. In particular, it was found that considering a plume at $25^{\circ} \mathrm{C}$ and utilizing a $\mathrm{Q} / \mathrm{A}=1.2 \mathrm{~m} / \mathrm{h}$, water recovery ranges from $36.24 \%\left(\mathrm{~T}=5.84^{\circ} \mathrm{C}\right.$ and $\mathrm{RH}=104.9 \%$ ) to more than $55 \%$ ( $\mathrm{T} \approx 10^{\circ} \mathrm{C}, \mathrm{T}_{\text {plume }} \approx 25^{\circ} \mathrm{C}$ and $\mathrm{RH}>140 \%$ ). Moreover, Fig. 4 shows the comparison between the results obtained through the simulations and those of the experimental measurements. It can be observed a good agreement between the experimental data and the model. This confirms the validity of the simulation study done and its suitability for predicting the performance of the condenser.

Good agreement between theoretical and experimental results was achieved also in the experiments performed considering the 


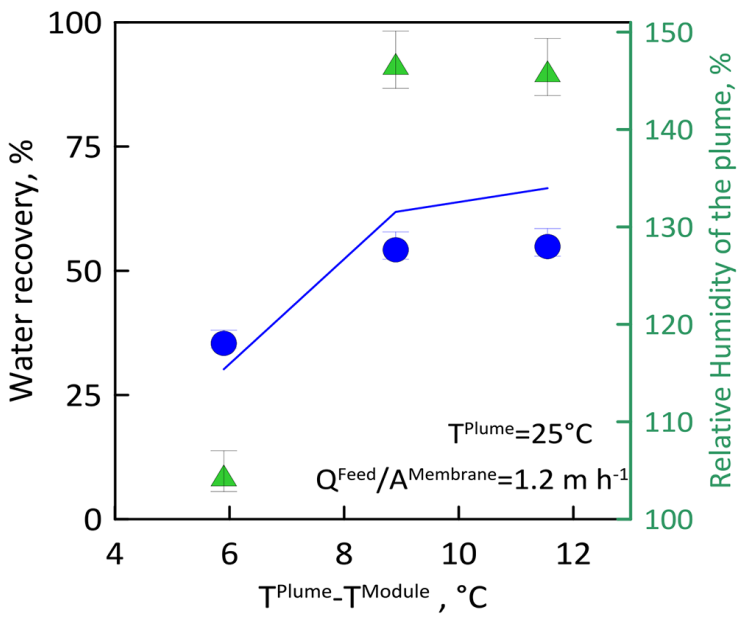

Fig. 4. Water recovery as a function of temperature difference between the plume and the membrane module, at different $\mathrm{RH}^{\text {Plume }}$. Symbols: experimental results; lines: simulation results. same temperature of the plume $\left(\approx 25^{\circ} \mathrm{C}\right)$ and at a higher $\mathrm{Q} / \mathrm{A}$ ratio (Fig. 5 on the left). In this case, the amount of recovered water increases from $46.0 \%\left(\mathrm{~T}=6^{\circ} \mathrm{C}\right)$ to more than $70 \%\left(\mathrm{~T} \approx 13.9^{\circ} \mathrm{C}\right)$ when the $\mathrm{RH}$ of the plume is as high as $\approx 142 \%$ (Fig. 5 on the left). On the contrary, as shown in Fig. 6 on the right and accordingly to simulations, even if $\mathrm{T}^{\text {Plume }}$ is higher $\left(\approx 30^{\circ} \mathrm{C}\right)$, the recovery of water is reduced by lowering $\mathrm{RH}^{\text {Plume }}$ to around $106 \%$. In particular, in the latter case water recovery passes from $32.12 \%$ for a $\mathrm{T}=$ $6.0^{\circ} \mathrm{C}$ to more than $64 \%$ for $\mathrm{T} \approx 15.95^{\circ} \mathrm{C}$.

The influence of $\mathrm{RH}$ on the amount of recovered water, maintaining almost constant $\mathrm{T}$, is clearly visible in Fig. 6 where it can be observed the increase of water recovery, at growing $\mathrm{RH}$, at two different $\mathrm{T}^{\text {Plume }}\left(40\right.$ and $45^{\circ} \mathrm{C}$ ). The highest value was $48.3 \%$, reached in the case of $\mathrm{T}^{\text {Plume }}=45^{\circ} \mathrm{C}$ when $\mathrm{T}=11.3^{\circ} \mathrm{C}$ and $\mathrm{RH}^{\text {Plume }}$ $=120 \%$.

As observed with the modeling, also at experimental level was found the increase of water recovery at growing $Q^{\text {Feed }} / A^{\text {Membrane }}$ ratio when all the other parameters ( $\mathrm{T}$ of the plume, $\mathrm{RH}$ and T) are kept constant (Table S2).

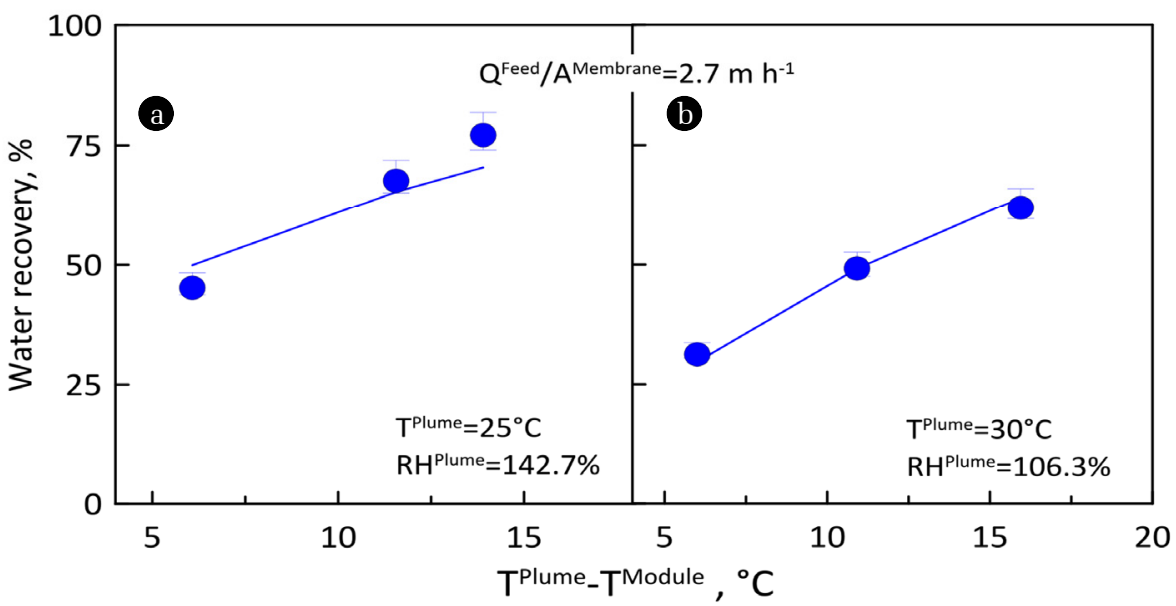

Fig. 5. Water recovery as a function of temperature difference between the plume and the membrane module, at different $T^{\text {Plume }}$. Symbols: experimental results; lines: simulation results.

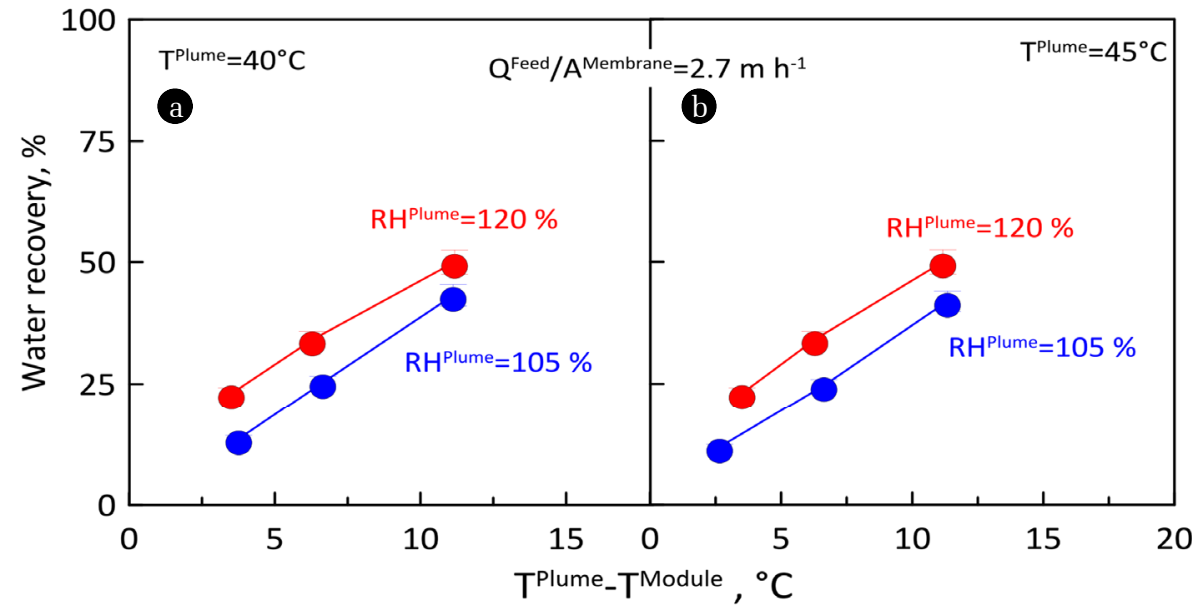

Fig. 6. Water recovery as a function of temperature difference between the plume and the membrane module, at different $\mathrm{RH}^{\text {Plume }}$. 


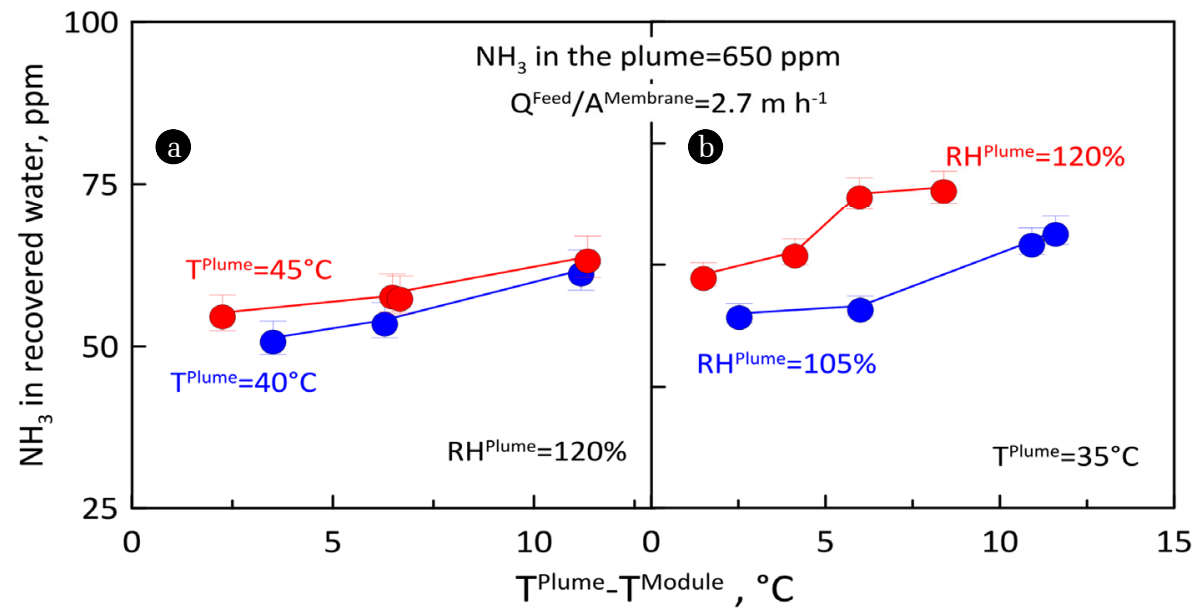

Fig. 7. $\mathrm{NH}_{3}$ in recovered water as a function of temperature difference between the plume and the membrane module, at different $\mathrm{T}^{\mathrm{Plume}}$ and $\mathrm{RH}^{\text {Plume }}$

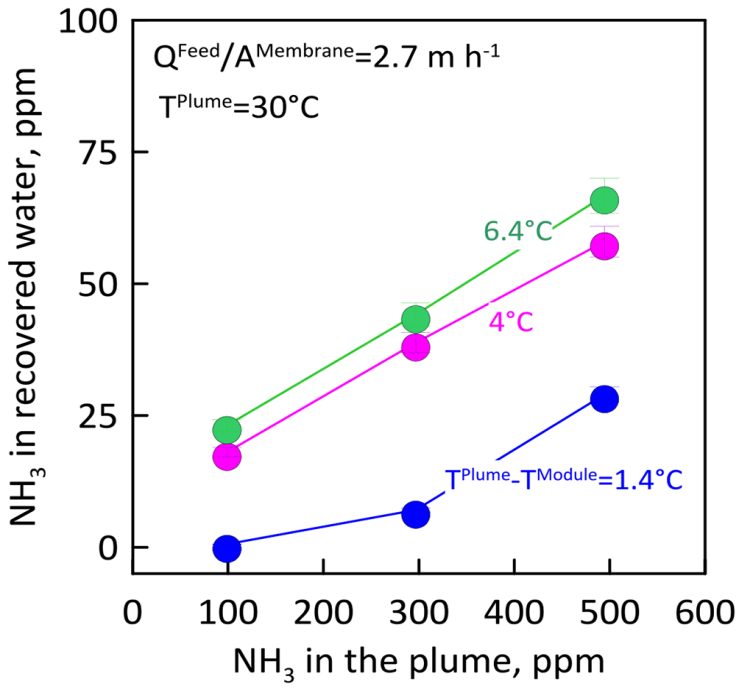

Fig. 8. $\mathrm{NH}_{3}$ in recovered water as a function of $\mathrm{NH}_{3}$ in the plume at different temperature difference between the plume and the membrane module.

The quality of liquid water recovered by membrane condenser is strictly affected by various parameters which influence the final contaminants content. As mentioned, in this work we considered the presence of $\mathrm{NH}_{3}$, as it is a contaminant usually present in the plume. For what concerns the composition of the recovered liquid water, results reported in Fig. 7 show the increase of $\mathrm{NH}_{3}$ concentration with the growing temperature difference DT between the fed plume and the membrane module (when the temperature of the fed plume is constant whereas the temperature of the membrane module decreases). This trend is because Henry's law constant of $\mathrm{NH}_{3}$ increases when the temperature of the membrane module decreases ( $\mathrm{T}$ in Eq. (2)):

$$
k_{H}=k_{H}^{0} \times \exp \left(\frac{-\triangle_{\text {soln }} H}{R}\left(\frac{1}{T}-\frac{1}{T^{0}}\right)\right)
$$

where

$$
\frac{\triangle_{\text {soln }} H}{R}=\frac{-d \ln k_{H}}{d(1 / T)}
$$

$k^{0}$ and $T^{0}$ refer to standard condition $(298.15 \mathrm{~K})$ and are equal to $61 \mathrm{~mol} \mathrm{l}^{-1} \mathrm{~atm}^{-1}$ and $4,200 \mathrm{~K}$, respectively.

As a consequence, $\mathrm{NH}_{3}$ solubility in aqueous solution rises when the membrane module temperature decreases.

Other parameters allowing controlling the concentration of $\mathrm{NH}_{3}$ are the initial feed concentration and the $\mathrm{RH}_{\text {feed. }}$. In fact, Fig. 7 and 8 show the increase of $\mathrm{NH}_{3}$ concentration in the recovered liquid water at growing $\mathrm{NH}_{3}$ concentration in the fed gaseous stream (Fig. 8) and $\mathrm{RH}^{\text {plume }}$ (Fig. 7).

In the performed experiments, the lowest $\mathrm{NH}_{3}$ concentration in the recovered water was found equal to $0.59 \mathrm{ppm}$ when the initial $\mathrm{NH}_{3}$ concentration in the feed was of about 100 ppm (Table S3).

\section{Conclusions}

In this work we analyzed, both theoretically and experimentally, the use of membrane condenser for the recovery of water vapor from the plume of a cooling tower. The simulation allowed predicting the process performance in a wide spectrum of operating conditions and identifying the minimum operating conditions for effectively recovering liquid water. It was found that the recovery of water can be increased with the grow of DT, $\mathrm{RH}$ and $\mathrm{Q} / \mathrm{A}$. Moreover, at $\mathrm{T}_{\text {plume }}$ low and equal to $25^{\circ} \mathrm{C}$, either a $\mathrm{Q} / \mathrm{A}$ ratio $\geq 2 \mathrm{mh}$ or $\mathrm{DT} \geq 2^{\circ} \mathrm{C}$ are necessary for obtaining positive amount of recovered water. It was also observed that the power needed for achieving the same percentage of recovered water increases with initial feed temperature.

The simulation study was validated through experiments performed on a membrane condenser prototype and a good agreement was found. Considering a plume at $25^{\circ} \mathrm{C}$ and utilizing $\mathrm{Q} / \mathrm{A}=$ $1.2 \mathrm{~m} / \mathrm{h}$, water recovery ranged from $36.24 \%\left(\mathrm{DT}=5.84^{\circ} \mathrm{C}\right.$ and 
$\mathrm{RH}=104.9 \%)$ to more than $55 \%\left(\mathrm{DT} \approx 10^{\circ} \mathrm{C}, \mathrm{RH}>140 \%\right)$ and these values increased at $\mathrm{Q} / \mathrm{A}$ ratio of $2.7 \mathrm{~m} / \mathrm{h}$ and $\mathrm{RH} \approx 142 \%$, passing from $46.04 \%$ (DT $\left.=6.0^{\circ} \mathrm{C}\right)$ to more than $70 \%\left(\mathrm{DT} \approx 13.9^{\circ} \mathrm{C}\right)$. As observed with the modeling, also at experimental level was found the increase of water recovery at growing $\mathrm{Q} / \mathrm{A}$ ratio when all the other parameters ( $\mathrm{T}$ of the plume, $\mathrm{RH}$ and $\mathrm{DT}$ ) are kept constant.

The experimental analyses performed considering the presence of $\mathrm{NH}_{3}$ in the fed gaseous stream revealed that the concentration of $\mathrm{NH}_{3}$ in the recovered liquid water increased with the growing temperature difference DT between the fed plume and the membrane module, at increasing $\mathrm{NH}_{3}$ concentration in the fed gaseous stream and at growing relative humidity of the feed. Therefore, apart the recovery of water, another important advantage of membrane condenser is the possibility to recover the chemicals necessary in the plant and, at the same time, to reduce their emissions. These are fundamental aspect to be considered in highly industrialized realities where the problems connected to water shortage and air pollution (inducing health problems and climate concerns) are becoming more and more pressing.

\section{Acknowledgments}

The H2020 is gratefully acknowledged for funding this work through the project "Materials \& Technologies for Performance Improvement of Cooling Systems in Power Plants (acronym MATChING)" (GA 686031).

\section{References}

1. Yunos KFM, Mazlan NA, Naim MNM, Baharuddin AS, Hassan AR. Ultrafiltration of palm oil mill effluent: Effect of operational pressures and stirring speed on performance and membranes fouling. Environ. Eng. Res. 2019;24:263-270.

2. Kim MK, Zoh KD. Occurrence and removals of micropollutants in water environment. Environ. Eng. Res. 2016;21:319-332.

3. Levy E, Bilirgen H, Jeong K, Kessen M, Samuelson C, Whitcombe C. Recovery of water from boiler flue gas. [dissertation]. Energy Research Center, Bethlehem (PA): Lehigh Univ.; 2008.

4. Michels B, Adamczyk F, Koch J. Retrofit of a flue gas heat recovery system at the Mehrum power plant. An example of power plant lifetime evaluation in practice. In: POWER-GEN Europe Conference; 25-27 May 2004; Barcelona, Spain. p. 10-11.

5. Jeong K, Kessen MJ, Bilirgen H, Levy EK. Analytical modeling of water condensation in condensing heat exchanger. Int. J. Heat Mass Transf. 2012;53:2361-2368.

6. Feeley TJ, Pletcher S, Carney B, McNemar AT. Department of energy/national energy technology laboratory's power plant-water R\&D program. In: Power-Gen International Conference; 2006.

7. Liu XH, Zhang Y, Qu KY, Jiang Y. Experimental study on mass transfer performances of cross flow dehumidifier using liquid desiccant. Energ. Convers. Manage. 2006;47:2682-2692.

8. Zurigat YH, Abu-Arabi MK, Abdul-Wahab SA. Air dehumidi- fication by triethylene glycol desiccant in a packed column. Energ. Convers. Manage. 2004;45:141-155.

9. Copen JH, Sulliva TB, Folkedahl BC, Carney B. Principles of flue gas water recovery system. In: Power-Gen International Conference; 6-8 December 2005; Las Vagas, NV, USA. p. 12.

10. Jeong K, Kessen MJ, Bilirgen H, Levy EK. Analytical modeling of water condensation in condensing heat exchanger. Int. J. Heat Mass Transf. 2012;53:2361-2368.

11. Metz S, Van de Ven W, Potreck J, Mulder M, Wessling M. Transport of water vapor and inert gas mixtures through highly selective and highly permeable polymer membranes. J. Membr. Sci. 2005;251:29-41.

12. Vane L, Namboodiri V, Lin G, Abar M, Alvarez F. Preparation of water-selective polybutadiene membranes and their use in drying alcohols by pervaporation and vapor permeation technologies. ACS Sust. Chem. Eng. 2016;4:4442-4450.

13. Huang Y, Merkel TC, Baker RW. Pressure ratio and its impact on membrane gas separation processes. J. Membr. Sci. 2014;463: 33-40.

14. Ito A. Dehumidification of air by a hygroscopic liquid membrane supported on surface of a hydrophobic microporous membrane. J. Membr. Sci. 2000;175:35-42.

15. Carney B. New technology will recover heat \& water from flue gas [internet]. Power Engineering; 23 August 2016 [cited 14 November 2016]. Available from: https://www.power-eng. com/articles/print/volume-120/issue-8/features/new-technology-will-recover-heat-water-from-flue-gas.html.

16. Lin C-X, Wang D, Bao A. Numerical modeling and simulation of condensation heat transfer of a flue gas in a bundle of transport membrane tubes. Int. J. Heat Mass Transf. 2013;60:41-50.

17. Bao A, Wang D, Lin C-X. Nanoporous membrane tube condensing heat transfer enhancement study. Int. J. Heat Mass Transf. 2015;84:456-462.

18. Wang D, Bao A, Kunc W, Liss W. Coal power plant flue gas waste heat and water recovery. Appl. Energ. 2012;91:341-348.

19. Zhang LZ, Zhu DS, Deng XH, Hua B. Thermodynamic modeling of a novel air dehumidification system. Energ. Build. 2005;37:279-286.

20. Wang T, Yue M, Qi H, Feron PH, Zhao S. Transport membrane condenser for water and heat recovery from gaseous streams: Performance evaluation. J. Membr. Sci. 2015;484:10-17.

21. Zhao S, Yan S, Wang DK, et al. Simultaneous heat and water recovery from flue gas by membrane condensation: Experimental investigation. Appl. Therm. Eng. 2017;113:843-850.

22. Chen H, Zhou Y, Cao S, et al. Heat exchange and water recovery experiments of flue gas with using nanoporous ceramic membranes. Appl. Therm. Eng. 2017;110:686-694.

23. Chen H, Zhou Y, Su X, et al. Experimental study of water recovery from flue gas using hollow micro-nano porous ceramic composite membranes. J. Ind. Eng. Chem. 2018;57:349-355.

24. Kim JF, Park A, Kim SJ, et al. Harnessing clean water from power plant emissions using membrane condenser technology. ACS Sust. Chem. Eng. 2018;6:6425-6433.

25. Macedonio F, Brunetti A, Barbieri G, Drioli E. Membrane condenser as a new technology for water recovery from humidified "waste" gaseous streams. Ind. Eng. Chem. Res. 2013;52:1160-1167. 26. Brunetti A, Santoro S, Macedonio F, Figoli A, Drioli E, Barbieri 
G. Waste gaseous streams: From environmental issue to source of water by using membrane condensers. CLEAN Soil Air Water 2014;42:1145-1153.

27. Macedonio F, Cersosimo M, Brunetti A, Barbieri G, Drioli E. Water recovery from humidified waste gas streams: Quality control using membrane condenser technology. Chem. Eng. Process. Process Intensif. 2014;86:196-203.

28. Brunetti A, Macedonio F, Barbieri G, Drioli E. Membrane engineering for environmental protection and sustainable industrial growth: Options for water and gas treatment. Environ. Eng. Res. 2015;20:307-328.

29. Macedonio F, Brunetti A, Barbieri G, Drioli E. Membrane condenser configurations for water recovery from waste gases. Sep. Purif. Technol. 2017;181:60-68.

30. Enright R, Miljkovic N, Al-Obeidi A, Thompson CV, Wang EN. Condensation on superhydrophobic surfaces: The role of local energy barriers and structure length scale. Langmuir 2012;28:14424-14432.

31. Kashchiev D. Nucleation: Basic theory with applications. 1st eds. Oxford: Butterworth-Heinemann; 2000.

32. Chen C-H, Cai Q, Tsai C, et al. Dropwise condensation on superhydrophobic surfaces with two-tier roughness. Appl. Phys. Lett. 2007;90:173108.

33. Wier KA, McCarthy TJ. Condensation on ultrahydrophobic surfaces and its effect on droplet mobility: Ultrahydrophobic surfaces are not always water repellant. Langmuir 2006;22: 2433-2436.

34. CORDIS. Final Report Summary - CAPWA (Capture of evaporated water with novel membranes) [Internet]. c2014 [cited 19 September 2018]. Available from: https://cordis.europa.eu/ result/rcn/146177_en.html.

35. MATChING - Materials technologies for performance improvement of cooling systems in power plant [Internet]. [cited 19 September 2018]. Available from: http://www.matching-project.eu.

36. Cooling Tower Institute. Legionellosis. Guideline: Best Practices for Control of Legionella [Internet]. c2008 [cited 19 September 2018]. Available from: https://www.cti.org/downloads/WTP-148.pdf. 